\title{
Impact of Climate Change on Water Resources in Taiwan
}

\author{
An-Yuan Tsai and Wen-Cheng Huang* \\ Department of Harbor and River Engineering, National Taiwan Ocean University, Keelung, Taiwan, ROC
}

Received 25 January 2011, accepted 15 April 2011

\begin{abstract}
This paper establishes a comprehensive assessment model to measure the regional impact of climate change on Taiwan's water resources. Working from future rainfall data simulated by Japan's high-resolution GCM model JMA/MRI TL959L60 in a SRES-A1B scenario, we first apply climate change to an assessment model of renewable water resources to estimate the volume of renewable water resources on a regional basis. We then conduct a water resources system simulation based on estimates of future water needs, regional reservoir effective capacity and renewable water resource volume. This paper uses three water resource assessment indicators: the annual water utilization ratio indicator, the water shortage indicator and the extreme event occurrence indicator. Through fuzzy comprehensive assessment, we divide the evaluation set into five levels: very good (L1), good (L2), fair (L3), poor (L4) and very poor (L5). Results indicate that, given the effects of future climate change (2080 - 2099) and the increase in water demand, future water resources conditions in northern and eastern Taiwan will not be significantly different from historical levels (1979 - 1998) and will maintain a "good" level (L2), while the conditions in southern Taiwan will visibly deteriorate from its historical "fair" level (L3) to "poor" (L4); and the future conditions for central Taiwan will be "poor" (L4). The initiation of adaptation options for water management in southern and central Taiwan would be needed by increasing reservoir capacity and reducing overall water use.
\end{abstract}

Key words: Climate change, GCM, Renewable water resources, Fuzzy comprehensive assessment

Citation: Tsai, A. Y. and W. C. Huang, 2011: Impact of climate change on water resources in Taiwan. Terr. Atmos. Ocean. Sci., 22, 507-519, doi: 10.3319/ TAO.2011.04.15.01(Hy)

\section{INTRODUCTION}

Among the impact of future climate change, hydrological changes will be among the most environmentally significant affecting the living habits of the human race. Current global research agrees that rising temperatures due to climate change are significantly changing global patterns of rainfall intensity and distribution. In 2007, the Intergovernmental Panel on Climate Change's (IPCC) Fourth Assessment Report (AR4) indicated that, according to the average of temperature simulations in 21 climate models under the A1B scenario, the average rates of global warming from 1980 to 1999 and 2080 to 2099 show a temperature difference of $2.5^{\circ} \mathrm{C}$, with temperatures expected to rise $3.3^{\circ} \mathrm{C}$ in East Asia.

Taiwan's geography is characterized by high, steep mountains and it's difficult to store rain water without reservoirs. However, good dam sites are difficult to find, the cost

\footnotetext{
* Corresponding author

E-mail:b0137@mail.ntou.edu.tw
}

of developing new water resources is high, and reservoir development needs to consider ecological and environmental protection. In addition, Taiwan's potential water supply has already been significantly developed. On the demand side, the Taiwan Water Resources Agency estimates in its "Taiwan Region Water Resource Development Program Plan" water demand will increase steadily through 2021. Therefore, an assessment of the effects of climate change on future water supply is critical for the development of long term adaptive strategies by relevant agencies to reduce potential harm.

Investigations into the potential effect of climate change on regional water supplies have been ongoing worldwide since the 1990s (Burn 1994; Arnell 1998; Hamlet and Lettenmaier 1999; Lane et al. 1999; Mimikou et al. 2000; Yu et al. 2002; Christensen et al. 2004; Lin et al. 2010). However, little research has been done on overall water resource evaluation systems under the impact of climate change. This study establishes a comprehensive assessment 
model for regional water resources which assesses regional changes in water supply under conditions of climate change. The model aims to provide relevant administration agencies with reference points for adaptive strategies for long term planning.

\section{RESEARCH PROCESS AND THEORETICAL DISCUSSION}

\subsection{Scaling and Research Process}

Following the scales from global scale to regional scale to basin scale, the ability of climate models will weaken for hydrological need (Xu and Singh 2004). The purpose of this study is to investigate regional water resources in Taiwan. The data from JMA/MRI TL959L60 GCM (Mizuta et al. 2006; Kitoh and Kusunoki 2008) is a high-resolution $20 \times$ $20 \mathrm{~km}$ spatial grid for daily rainfall. Downscaling would not be required in this study.

Figure 1 shows the flowchart of this study's comprehensive assessment model for regional water resources, beginning with the estimation of regional renewable water resources through a model under the influence of climate change, and followed by a comprehensive assessment of water demand and regional effective reservoir capacity. The water resource evaluation indicators established by this study are used in the process of system simulation and fuzzy comprehensive assessment. This study provides a comparison of Taiwan's historical (1979 - 1998) and future (2080 - 2099) water resource under the influence of climate change.

\subsection{Estimating Regional Renewable Water Resources Under Climate Change}

In theory, renewable water resources (i.e., surface and groundwater flows from rain and snowfall) can be used efficiently, and research has already produced estimation methods (Pike 1964; Kite et al. 1994; Xu et al. 1996; Arnell 1999; Xu and Singh 2004; Shiklomanov et al. 2010). This paper follows earlier studies of estimating renewable water resources (Tsai and Huang 2011) as follows:

Figure 2 shows the flowchart for estimating regional renewable water resources under the impact of climate change. First we gather daily rainfall data for 1979 - 1998 from regional rainfall stations, and simulate daily rainfall data from Japan's JMA/MRI TL959L60 mode under SRESA1B condition for present day (1979 - 1998) and future (2080 - 2099). The modeling data are then corrected by use of the Quadrant Transformation Method (QTM). We further apply the Thornthwaite method to project evapotranspiration. Finally, the corrected future (2080 - 2099) precipitation, less projected evapotranspiration returns the future volume of renewable water resources.

\subsubsection{Quadrant Transformation Method (QTM)}

Given that the GCM method frequently over or underestimates phenomena, to obtain more accurate simulation values we propose to use the Quadrant Transformation Method for data correction. Comprehensive historical data from simulations from Japan's JMA/MRI model under SRES-A1B condition were corrected by QTM. As shown in Fig. 3, the duration curve for JMA/MRI simulated rainfall data for the Shihmen Rainfall Measurement Station from 2080 - 2099 starts in the third quadrant. Next, through the relation of the duration curves of the first and fourth quadrants we obtain the corrected rainfall duration curve in the second quadrant. In the correction process, the difference between the duration curves of the first and fourth quadrant is caused by the GCM model, while the difference between

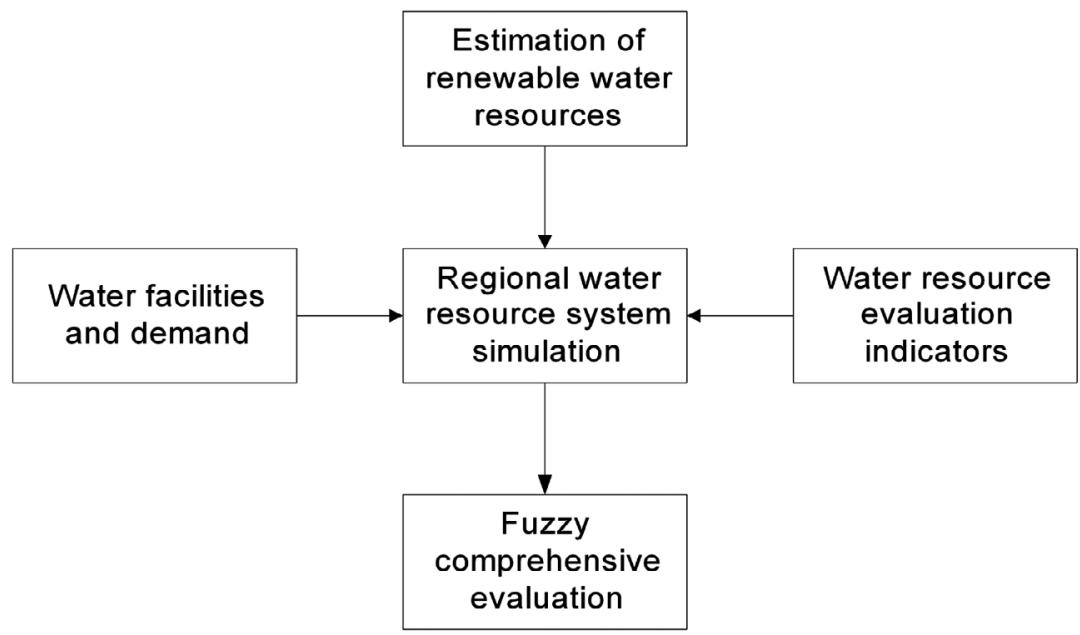

Fig. 1. Flowchart for the comprehensive assessment model for regional water resources under climate change. 
the duration curves of the third and fourth quadrants is due to climate change. The quadrant transformation of the simulation data provides the comprehensive corrected result.

\subsubsection{Thornthwaite Method}

Many models have been developed to estimate potential evapotranspiration (Thornthwaite 1948; Turc 1961; Priestley and Taylor 1972; Snyder 1992). Each model considers different factors and the selection of a model depends on conditions including the research area's spatial scale, temporal scale, regional characteristics and the acquisition of model factors.

The future output data of global climate models focus primarily on rainfall and temperature values, thus providing insufficient information for many models to estimate potential evapotranspiration. This research estimates regional evapotranspiration through the well-established Thronthwaite method, which requires only two factors: temperature and sunshine duration. The use of this empirical formula to estimate potential evapotranspiration is described as follows:

$i_{m}=\left(t_{m} / 5\right)^{1.514}$

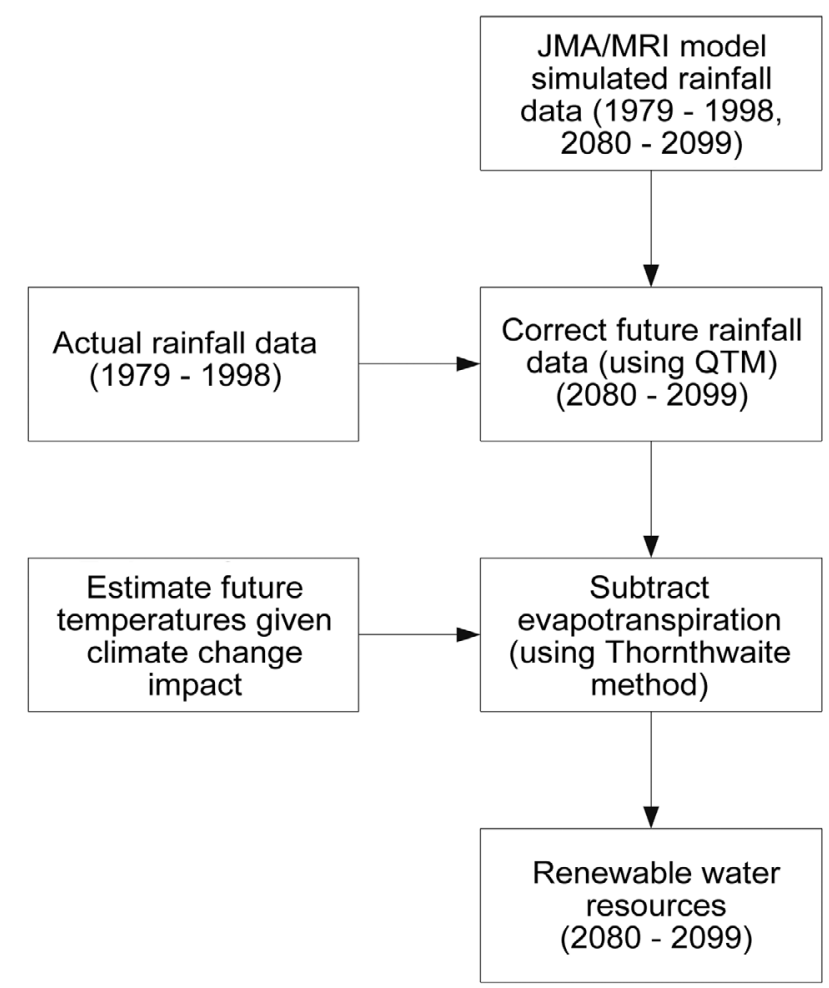

Fig. 2. Flowchart for estimating regional renewable water resources under the impact of climate change.

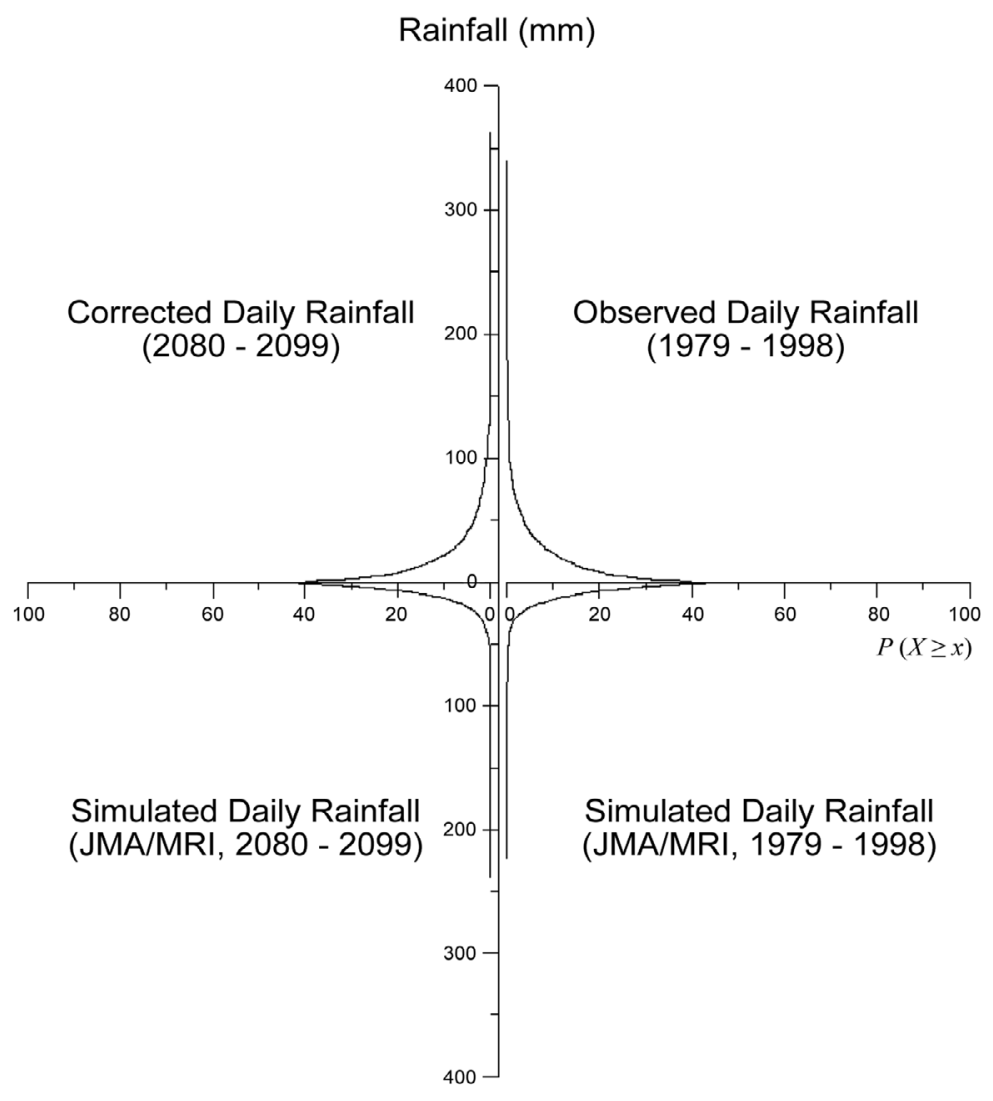

Fig. 3. Quadrant conversion diagram for Shihmen station. 
$I=\sum_{m=1}^{12} i_{m}$

$P E_{m}^{s}=1.6\left(10 t_{m} / I\right)^{a}$, if $t_{m}<26.5^{\circ} \mathrm{C}$

$a=0.000000675 I^{3}-0.0000771 I^{2}+0.01792 I+0.49239$

$P E_{m}=C_{m} \times P E_{m}^{s}$

where $i_{m}$ is the monthly index; $t_{m}$ is the average temperature for each month $\left({ }^{\circ} \mathrm{C}\right) ; I$ is the heat index, a total value for monthly indices for the whole year; $P E_{m}^{s}$ is the uncorrected monthly potential evapotranspiration $(\mathrm{cm})$ when $t_{m} \geqq 26.5^{\circ} \mathrm{C}$ obtained in the other table; $a$ is the coefficient of regional change; $P E_{m}$ is the corrected monthly potential evapotranspiration value (cm); and $C_{m}$ is the corrected coefficient for each month.

\subsubsection{Estimating Renewable Water Resource Volume}

This study references the concept of water balance: rainfall volume $=$ evapotranspiration volume + renewable water resource volume. Monthly renewable water resource volume is estimated as follows (Gustard et al. 1992; Rees et al. 1997):

$r=a \times P_{m}+b, \quad r \leq 1$

$A E_{m}= \begin{cases}r \times P E_{m} & \text {, if } P_{m} \geq r \times P E_{m} \\ P_{m} & \text {, if } P_{m}<r \times P E_{m}\end{cases}$

$R_{m}=\left(P_{m}-A E_{m}\right) \times \frac{A}{10000}$

where $r$ is the adjustment factor; $a, b$ are coefficients; $P_{m}$ is monthly rainfall $(\mathrm{cm}) ; A E_{m}$ is monthly evapotranspiration (cm); $P E_{m}$ is the monthly potential evapotranspiration (cm); $R_{m}$ is monthly renewable water resource volume $\left(\mathrm{m}^{3}\right)$; and $A$ is regional area $\left(\mathrm{km}^{2}\right)$.

\subsection{Water Resource Evaluation Indicators}

Water resource evaluation should account for regional runoff (renewable water resources), water needs (demand) and system indicators for a system simulation. This study uses three assessment indicators to produce a comprehensive picture of water resources, i.e., 1) water utilization ratio indicator, 2) water shortage indicator, and 3) extreme event occurrence indicator.

This paper uses fuzzy theory to establish a five level assessment set (L): L = [very good (L1), good (L2), fair (L3), poor (L4), very poor (L5)], and considers an attribute set $(A)$ : $A=$ (Annual water utilization ratio, water shortage, extreme event occurrence). Detailed descriptions of fuzzy sets and their operations can be found in Chen and Hwang (1992) and Zimmermann (1991). Each indicator and membership function is described below.

\subsubsection{Annual Water Utilization Ratio Indicator}

The annual water utilization ratio (expressed by AU) is the proportion of annual regional water supply to total renewable water resources, represented by the average value for each year's annual water utilization as follows:

$A U=\frac{1}{N} \sum_{i=1}^{N}\left(\frac{X_{i}}{R_{i}}\right)$

where $A U$ is annual water utilization ratio; $N$ is the number of years; $X_{i}$ is total water use in year $i$; and $R_{i}$ is total renewable water resources in year $i$.

The establishment of the fuzzy membership function is primarily based on information from the World Water Council website (http://www.worldwatercouncil.org), which divides global water supply utilization into five levels for analysis: 0 - 0.1 No stress, $0.1-0.2$ Low stress, $0.2-0.4$ Moderate stress, $0.4-0.8$ High stress and above 0.8 Very high stress. These non-linear brackets are adopted as the non-linear expressions for this study's membership function. Figure 4 shows fuzzy membership function graph for annual utilization ratio, in which $\mu_{j}$ is the standardized membership function $\left(0 \leqq \mu_{j} \leqq 1\right)$. The fuzzy membership function is displayed as:

$\mu_{L 1}(A U)= \begin{cases}1 & , \text { if } A U \leq 0.05 \\ \left(\frac{0.15-A U}{0.15-0.05}\right)^{2} & , \text { if } 0.05<A U \leq 0.15 \\ 0 & \text {, if } A U>0.15\end{cases}$

$\mu_{L 2}(A U)= \begin{cases}0 & \text {, if } A U \leq 0.05 \\ 1-\left(\frac{0.15-A U}{0.15-0.05}\right)^{2} & , \text { if } 0.05<A U \leq 0.15 \\ \left(\frac{0.3-A U}{0.3-0.15}\right)^{2} & \text {, if } 0.15<A U \leq 0.3 \\ 0 & \text {, if } A U>0.3\end{cases}$

$\mu_{L 3}(A U)= \begin{cases}0 & \text {, if } A U \leq 0.05 \\ 1-\left(\frac{0.3-A U}{0.3-0.15}\right)^{2} & , \text { if } 0.15<A U \leq 0.3 \\ \left(\frac{0.65-A U}{0.65-0.3}\right)^{2} & , \text { if } 0.3<A U \leq 0.65 \\ 0 & \text {, if } A U>0.65\end{cases}$ 


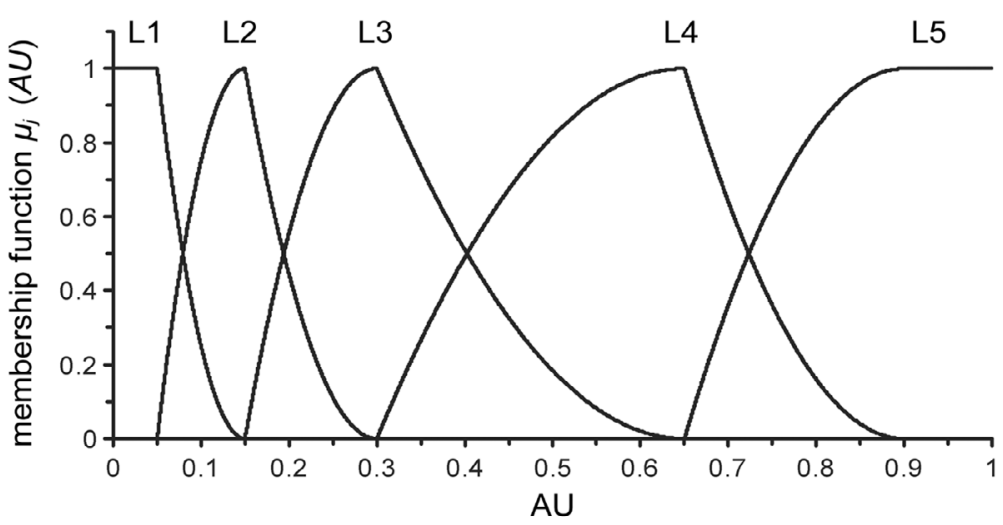

Fig. 4. Membership function of annual utilization ratio.

$$
\begin{aligned}
& \mu_{L 4}(A U)= \begin{cases}0 & \text {, if } A U \leq 0.3 \\
1-\left(\frac{0.65-A U}{0.65-0.3}\right)^{2} & , \text { if } 0.3<A U \leq 0.65 \\
\left(\frac{0.9-A U}{0.9-0.65}\right)^{2} & \text {, if } 0.65<A U \leq 0.9 \\
0 & , \text { if } A U>0.9\end{cases} \\
& \mu_{L 5}(A U)= \begin{cases}0 & \text { if } A U \leq 0.65 \\
1-\left(\frac{0.9-A U}{0.9-0.65}\right)^{2} & , \text { if } 0.65<A U \leq 0.9 \\
1 & \text {, if } A U>0.9\end{cases}
\end{aligned}
$$

\subsubsection{Water Shortage Indicator}

The water shortage indicator considers two sub-factors: 1) Shortage Index (SI), and 2) additional reservoir capacity required such that $\mathrm{SI} \leqq 1$ (AC), which are summarized as follows:

1) Shortage Index (US Army 1963)

$S I=\frac{100}{N} \sum_{i=1}^{N}\left(\frac{S_{i}}{D_{i}}\right)^{2}$

where $S I$ is the shortage index; $N$ is the number of years; $S_{i}$ is the total water shortage for year $i$; and $D_{i}$ is total water demand for the year i.

The fuzzy membership function is similar to the annual utilization non-linear type in considering degree of tolerance for general water resource supply and demand. Table 1 gives the representative value of each membership function, where the membership grade equals one.

2) Additional reservoir capacity required such that $\mathrm{SI} \leqq 1$

For water supply and demand, generally SI $=1$ as the set standard, and water supply and demand are stable as SI $<1$. However, if SI $>1$, to avoid shortages one should consider expanding the existing water supply or reducing demand. In this study the increased volume is the additional reservoir capacity such that $\mathrm{SI} \leqq 1$. By measuring the feasibility and difficulty of increasing Taiwan's current reservoir capacity, the representative values of membership functions for the additional reservoir capacity (AC) are described in Table 1.

\subsubsection{Extreme Event Occurrence Indicator}

This study used two factors to measure the impact level of extreme water shortage events, with a return period set at $\mathrm{T}=10$ years: 1 ) maximum months of consecutive shortage $\left(\mathrm{RL}_{10}\right)$, and 2) maximum continuous water shortage rate $\left(\mathrm{RS}_{10}\right)$.

1) Maximum months of consecutive shortage at $T=10$ years

Run theory (Salas et al. 1980) and Pearson Type III frequency analysis (Haan 1977) were used through water resource system simulations to obtain the maximum months of consecutive shortage. To ensure rigorous calculations, for this study, months with shortages of below $10 \%$ were not considered to be shortage months. The representative value of each fuzzy membership graph for $\mathrm{RL}_{10}$ can be found in Table 1.

2) Maximum continuous shortage rate at $T=10$ years

Continuous shortage rate is defined as the ratio of the total volumes of continuous shortage (run-sum) to annual water demand. Similar to the calculation of maximum months of consecutive shortage, Table 1 shows the representative values of membership functions for the maximum continuous shortage rate, given $\mathrm{T}=10$ years $\left(\mathrm{RS}_{10}\right)$.

\subsection{Fuzzy Comprehensive Assessment}

Based on the three above-mentioned indicators and their sub-indicators, our integrated assessment is described as follows: 
Table 1. Representative values of fuzzy membership functions.

\begin{tabular}{ccccccc}
\hline \multirow{2}{*}{ Evaluation factor } & \multicolumn{5}{c}{ Location of membership function where $\boldsymbol{\mu}_{j}=\mathbf{1}$} & \multirow{2}{*}{ Unit } \\
\cline { 2 - 5 } & Very good $(\mathbf{L 1})$ & Good $(\mathbf{L})$ & Fair $(\mathbf{L})$ & Poor $(\mathbf{L})$ & Very poor $(\mathbf{L 5})$ & \\
\hline $\mathrm{AU}$ & $0 \sim 5$ & 15 & 30 & 65 & $90 \sim$ & $\%$ \\
$\mathrm{SI}$ & $0 \sim 0.1$ & 1 & 2 & 3.5 & $5.5 \sim$ & - \\
$\mathrm{AC}$ & 0 & 0.5 & 1 & 2 & $4 \sim$ & $10^{8} \mathrm{~m}^{3}$ \\
$\mathrm{RL}_{10}$ & $0 \sim 0.5$ & 1 & 2 & 3.5 & $5.5 \sim$ & months \\
$\mathrm{RS}_{10}$ & $0 \sim 2$ & 6 & 12 & 20 & $30 \sim$ & $\%$ \\
\hline
\end{tabular}

a) Annual water utilization ratio is a single evaluation factor, with the fuzzy evaluation set $R^{U}$ :

$R^{U}=\left(r_{1}^{u}, r_{2}^{u}, r_{3}^{u}, r_{4}^{u}, r_{5}^{u}\right)$

where $r_{1}^{u} \sim r_{5}^{u}$ are the membership function values for the annual utilization ratios for each level (L1 L5).

b) The "Shortage Index" and the "additional reservoir capacity required such that $\mathrm{SI} \leqq 1$ " combine to form the water shortage indicator. Calculations are as follows:

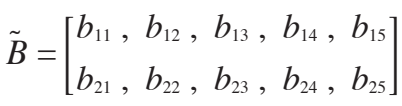

$R^{s}=W_{s} \cdot \tilde{B}=\left(r_{1}^{s}, r_{2}^{s}, r_{3}^{s}, r_{4}^{s}, r_{5}^{s}\right)$

where $\tilde{B}$ is the fuzzy evaluation matrix, in which $b_{11} \sim b_{15}$ and $b_{21} \sim b_{25}$ are respectively the "Shortage Index" and the "additional reservoir capacity required such that $\mathrm{SI} \leqq 1$ " corresponding to the membership function values for each level (L1 $\sim \mathrm{L} 5) . R^{S}$ is an assessment set for the shortage indicator, in which $r_{1}^{s} \sim r_{5}^{s}$ is obtained by multiplying the membership value for each sub-factor by the weighting. $W_{S}$ is the weight for each sub-factor. This research regards the weight of both evaluation factors to be equal, with a weight distribution of 0.5 .

c) The extreme event occurrence indicator combines the "Maximum months of consecutive shortage, $\mathrm{T}=10$ years" and the "Maximum continuous shortage rate, $\mathrm{T}=10$ years" evaluation factors using the same method as the water Shortage Indicator:

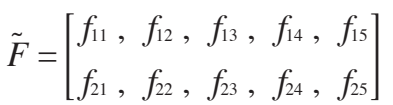

$R^{E}=W_{E} \cdot \tilde{F}=\left(r_{1}^{e}, r_{2}^{e}, r_{3}^{e}, r_{4}^{e}, r_{5}^{e}\right)$

where $\tilde{F}$ is the fuzzy evaluation matrix, in which $f_{11} \sim f_{15}$ and $f_{21} \sim f_{25}$ are the membership function values of the level (L1 $\sim$ L5) corresponding to each evaluation factor. $R^{E}$ is the extreme event occurrence set. This research regards the weight of both evaluation factors to be equal, with a weight distribution of 0.5 .

d) Overall, the water resource evaluation combines three indicators using the operation of the fuzzy comprehensive assessment set as follows:

$\tilde{R}=\left[\begin{array}{l}r_{1}^{u}, r_{2}^{u}, r_{3}^{u}, r_{4}^{u}, r_{5}^{u} \\ r_{1}^{s}, r_{2}^{s}, r_{3}^{s}, r_{4}^{s}, r_{5}^{s} \\ r_{1}^{e}, r_{2}^{e}, r_{3}^{e}, r_{4}^{e}, r_{5}^{e}\end{array}\right]$

$Z=W \cdot \tilde{R}=\left(z_{1}, z_{2}, z_{3}, z_{4}, z_{5}\right)$

where $\tilde{R}$ is the fuzzy evaluation matrix of three indicators. $Z$ is the water resources fuzzy comprehensive assessment set, in which $z_{1} \sim z_{5}$ is the assessment value for each level (L1 L5). W is the weight value of each indicator. Here we use the Analytic Hierarchy Process (AHP) to determine the weight in $\mathrm{W}$. The comparison matrix is:

$P=\left[\begin{array}{lll}P^{u} & P^{s} & P^{e} \\ 1 & 1 & 2 \\ 1 / 2 & 1 & 3 \\ 1 / 3 & 1\end{array}\right] P^{P^{e}}$

where $P$ is the comparison matrix, the superscripts $u, s$, and $e$ respectively represent the annual water utilization ratio indicator, the water shortage indicator and the extreme event occurrence indicator. As a result, $W=[0.387,0.443$, $0.169]$.

e) Finally, the status of the water resource comprehensive assessment is determined when the cumulative assessment value $z_{i}$ exceeds 0.5 ordered from very good level (L1) to very poor level (L5), that is, when it fulfills $\sum_{i=1}^{n} z_{i} \geq 0.5>\sum_{i=1}^{n-1} z_{i}$, then the rating $\mathrm{Ln}$ is the current level (Huang and Hsieh 2010). 


\section{CASE STUDY}

\subsection{Researched Region and Basic Data Analysis}

This research adopts a common partitioning by the Water Resources Agency, dividing Taiwan into four regions: North $\left(7353 \mathrm{~km}^{2}\right)$, Center $\left(10507 \mathrm{~km}^{2}\right)$, South $\left(10004 \mathrm{~km}^{2}\right)$ and East $\left(8144 \mathrm{~km}^{2}\right)$. As shown in Fig. 5, the basis for the partitioning is not only geographic, but also similarities in climate and hydrological characteristics, water supply, water conservation facilities, and other factors related to supply and demand of water. Table 2 shows Water Resources Agency statistics for each region's effective reservoir capacity, annual average rainfall, monthly rainfall exceedance probability (by using an exceedance probability of 0.5 as a reference for wet/dry distribution), annual renewable water resource volume, historical annual water demand volume and estimated future annual water demand. In total, 83 rainfall stations in the North (19 stations), Center (24), South (24) and East (16) regions are selected, as shown in Fig. 5.

\subsection{Hydrologic Estimation for the Future (2080 - 2099)}

The regional future (2080 - 2099) annual average rainfall estimates, wet/dry distribution, annual average evapotranspiration and annual renewable water resources are shown in Table 3 . In detail, please refer to the paper by the authors (Tsai and Huang 2011).

As shown in Tables 2 and 3, the influence of climate change on the wet/dry difference in the north region will increase slightly in the future, with a slight change in the

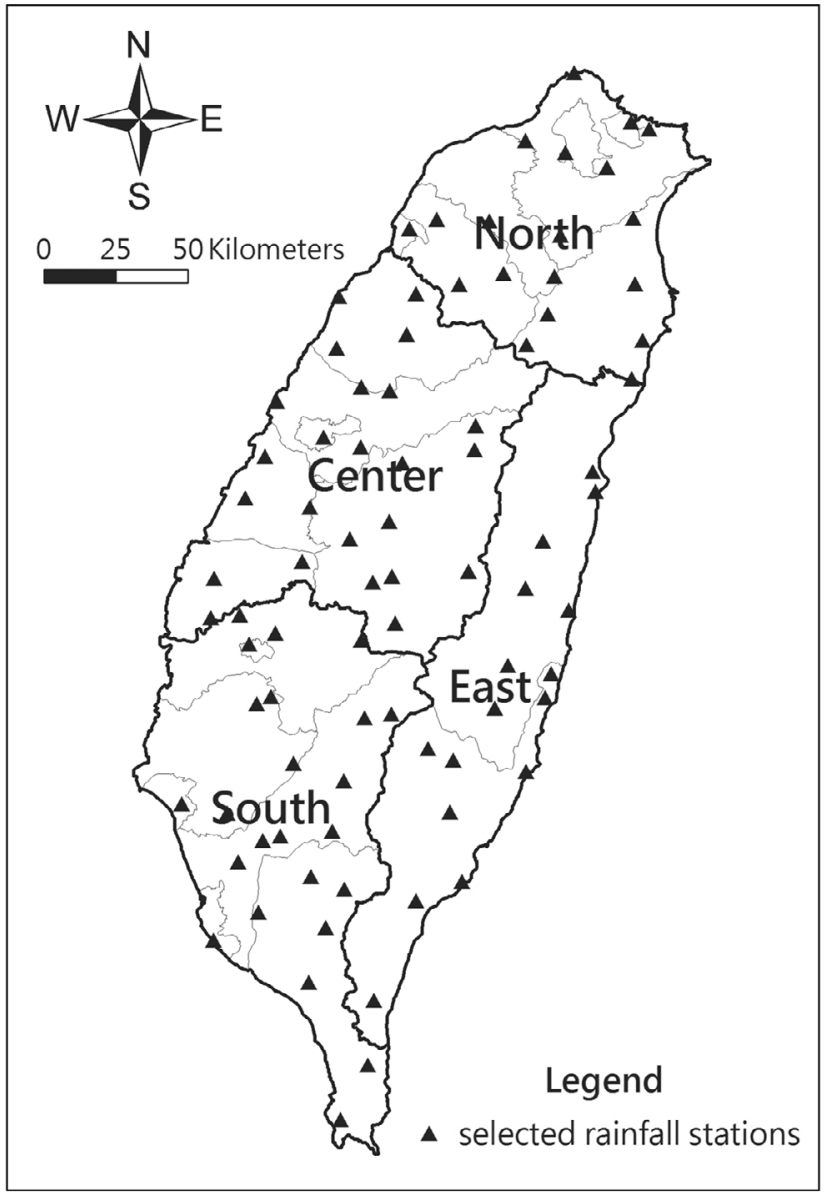

Fig. 5. Taiwan's water resource regions and selected rainfall stations.

Table 2. Basic data from the Water Resources Agency.

\begin{tabular}{lcccccc}
\hline Item (Period) & North & Center & South & East & Total & Unit \\
\hline Effective reservoir capacity (2009) & 602.2 & 534.4 & 786.7 & 0.67 & 1924 & $10^{6} \mathrm{~m}^{3}$ \\
Annual average rainfall (1979- 1998) & 2961 & 2003 & 2513 & 2328 & 2414 & $\mathrm{~mm}$ \\
Wet/dry distribution (1979-1998) & $56.0 / 44.0$ & $75.7 / 24.3$ & $89.0 / 11.0$ & $73.1 / 26.9$ & - & $\%$ \\
Annual renewable water resources (1949- 2000) & 157.5 & 158.2 & 187.1 & 172.5 & 675.3 & $10^{8} \mathrm{~m}^{3}$ \\
Historical water demand (1979 - 1998) & 38.79 & 65.74 & 37.89 & 23.53 & 165.95 & $10^{8} \mathrm{~m}^{3}$ \\
Future water demand (2080 - 2099) & 42.76 & 69.71 & 46.26 & 24.96 & 183.69 & $10^{8} \mathrm{~m}^{3}$ \\
\hline
\end{tabular}

Table 3. Estimated results (2080 - 2099)*.

\begin{tabular}{|c|c|c|c|c|c|c|}
\hline Item & North & Center & South & East & Total & Unit \\
\hline Annual average rainfall & 2932 & 1836 & 2209 & 2239 & 2255 & $\mathrm{~mm}$ \\
\hline Wet/dry distribution & $62.6 / 37.4$ & $74.4 / 25.6$ & $89.8 / 10.2$ & $70.3 / 29.7$ & - & $\%$ \\
\hline Annual average evapotranspiration & 70.45 & 59.11 & 70.54 & 19.78 & 219.88 & $10^{8} \mathrm{~m}^{3}$ \\
\hline Annual renewable water resources & 145.2 & 133.8 & 150.4 & 162.6 & 592.0 & $10^{8} \mathrm{~m}^{3}$ \\
\hline
\end{tabular}

* Tsai and Huang (2011) 
central region, no change in the south region, and a slight reduction in the east region. In terms of annual rainfall, each region will see its annual average rainfall drop from past levels. Average annual rainfall for Taiwan as a whole will drop from 2414 mm (1979 - 1998) to 2255 mm (2080 - 2099). The average annual renewable water resource volume for Taiwan as a whole will drop by $12.3 \%$ from 67.5 to $59.2 \mathrm{~km}^{3}$, as compared with the average from 1949 through 2000 .

\subsection{Regional Water Resource System Simulation}

This study would regard regional reservoir effective capacity as a virtual reservoir, paired with renewable water resources and water demand to implement a water resources system simulation based on monthly time units. The balancing equation is:

$Q_{t+1}^{\prime}=Q_{t}+R_{t}-D_{t}$

$Q_{t+1}= \begin{cases}0, & \text { if } Q_{t+1}^{\prime} \leq 0, \text { then } S_{t}=D_{t}-Q_{t}-R \\ Q_{t+1}^{\prime} & , \text { if } 0<Q_{t+1}^{\prime}<K \\ K & , \text { if } Q_{t+1}^{\prime} \geq K\end{cases}$

where $Q_{t}$ is the effective storage capacity starting at time $t$; $R_{t}$ is renewable water resources at time $t ; D_{t}$ is water demand at time $t ; Q_{t+1}$ is effective storage capacity starting at time $t+1 ; S_{t}$ is the water shortage volume at time $t$; and $K$ is the effective capacity of the pan-regional virtual reservoir.

Table 4 shows the various evaluation results, respectively, for evaluating regional historical (1979 - 1998) and future (2080 - 2099) water resources through system simulation. This study assumes that effective future (2080 - 2099) reservoir capacity will remain at past levels.

\subsection{Water Resource Fuzzy Comprehensive Assessment}

The performance values of each regional evaluation factor are calculated using the fuzzy membership function.
Tables 5a to d show the historical (1979 - 1998) and future (2080 - 2099) fuzzy membership function values for each evaluation factor. By use of the fuzzy comprehensive assessment, Table 6 gives the regional evaluation levels for the past and future.

\section{DISCUSSION}

\subsection{Historical Water Resource Assessment}

a) The results of this study indicate that the historical (1979 - 1998) water resource comprehensive condition for northern and eastern Taiwan was "good" (L2). Aside from the annual utilization ratio indicator for northern Taiwan at L3, on average other indicators were all better than L3, indicating that the model analysis results are consistent with reality.

b) However, the historical water resource comprehensive condition for central Taiwan was "poor" (L4), primarily because of high water demand in this region, averaging 65.7 $\times 10^{8} \mathrm{~m}^{3}$ annually, of which $55.3 \times 10^{8} \mathrm{~m}^{3}$ was used by agriculture (including aquaculture use). In theory, "poor" (L4) indicates frequent severe water shortages, but actual past water demand and supply does not conform to the model analysis results. This is due to large scale aquifer depletion in the region, primarily in the Changhua and Yunlin areas, with as many as 120000 wells pumping an annual average of $20 \times 10^{8} \mathrm{~m}^{3}$, exceeding the annual average recharge rate by $5.7 \times 10^{8} \mathrm{~m}^{3}$, and thus resulting in severe land subsidence in the region.

Given strict controls on excessive pumping, along with appropriate development and use, groundwater resources can effectively function as underground reservoirs to meet the water use needs of the Changhua and Yunlin areas. Assuming that over-pumping volume $\left(5.7 \times 10^{8} \mathrm{~m}^{3}\right)$ is deducted from water needs, simulations using this study's model show that, on the condition that SI $=1$ (i.e., matching actual conditions in the Central region), an additional reservoir capacity of $2.94 \times 10^{8} \mathrm{~m}^{3}$,will be required and we can infer that this effective capacity will come from the region's underground reservoirs. Conservatively assuming an under-

Table 4. Regional historical (1979 - 1998) and future (2080 - 2099) evaluation factor performance.

\begin{tabular}{|c|c|c|c|c|c|c|c|c|c|}
\hline \multirow{2}{*}{ Evaluation factor } & \multicolumn{2}{|c|}{ North } & \multicolumn{2}{|c|}{ Center } & \multicolumn{2}{|c|}{ South } & \multicolumn{2}{|c|}{ East } & \multirow{2}{*}{ Unit } \\
\hline & Historical & Future & Historical & Future & Historical & Future & Historical & Future & \\
\hline $\mathrm{AU}$ & 25.71 & 31.61 & 37.77 & 45.97 & 20.52 & 28.39 & 14.29 & 15.44 & $\%$ \\
\hline SI & 0.07 & 0.06 & 2.65 & 2.88 & 1.29 & 2.67 & 0.04 & 0.64 & - \\
\hline $\mathrm{AC}$ & 0 & 0 & 4.50 & 4.49 & 0.94 & 3.95 & 0 & 0 & $10^{8} \mathrm{~m}^{3}$ \\
\hline $\mathrm{RL}_{10}$ & 0.75 & 0.87 & 4.24 & 5.13 & 3.61 & 4.43 & 1.14 & 1.64 & months \\
\hline $\mathrm{RS}_{10}$ & 3.89 & 3.70 & 20.59 & 22.25 & 17.75 & 25.72 & 3.43 & 12.92 & $\%$ \\
\hline
\end{tabular}


Table 5. (a) Performance of fuzzy membership function values in the north region.

\begin{tabular}{|c|c|c|c|c|c|c|c|c|}
\hline \multirow{2}{*}{ Evaluation factor } & \multirow{2}{*}{ Period } & \multirow{2}{*}{ Performance value } & \multirow{2}{*}{ Unit } & \multicolumn{5}{|c|}{ Membership grade } \\
\hline & & & & L1 & $\mathbf{L 2}$ & $\mathbf{L 3}$ & L4 & L5 \\
\hline \multirow[b]{2}{*}{$\mathrm{AU}$} & historical & 25.71 & \multirow[b]{2}{*}{$\%$} & 0 & 0.08 & 0.92 & 0 & 0 \\
\hline & future & 31.61 & & 0 & 0 & 0.91 & 0.09 & 0 \\
\hline \multirow{2}{*}{ SI } & historical & 0.07 & \multirow{2}{*}{-} & 1 & 0 & 0 & 0 & 0 \\
\hline & future & 0.06 & & 1 & 0 & 0 & 0 & 0 \\
\hline \multirow{2}{*}{$\mathrm{AC}$} & historical & 0 & \multirow{2}{*}{$10^{8} \mathrm{~m}^{3}$} & 1 & 0 & 0 & 0 & 0 \\
\hline & future & 0 & & 1 & 0 & 0 & 0 & 0 \\
\hline \multirow[b]{2}{*}{$\mathrm{RL}_{10}$} & historical & 0.75 & \multirow{2}{*}{ months } & 0.25 & 0.75 & 0 & 0 & 0 \\
\hline & future & 0.87 & & 0.06 & 0.94 & 0 & 0 & 0 \\
\hline \multirow{2}{*}{$\mathrm{RS}_{10}$} & historical & 3.89 & \multirow{2}{*}{$\%$} & 0.28 & 0.72 & 0 & 0 & 0 \\
\hline & future & 3.70 & & 0.33 & 0.67 & 0 & 0 & 0 \\
\hline
\end{tabular}

Table 5. (b) Performance of fuzzy membership function values in the central region.

\begin{tabular}{|c|c|c|c|c|c|c|c|c|}
\hline \multirow{2}{*}{ Evaluation factor } & \multirow{2}{*}{ Period } & \multirow{2}{*}{ Performance value } & \multirow{2}{*}{ Unit } & \multicolumn{5}{|c|}{ Membership grade } \\
\hline & & & & L1 & L2 & $\mathbf{L 3}$ & L4 & L5 \\
\hline \multirow[b]{2}{*}{$\mathrm{AU}$} & historical & 37.77 & \multirow[b]{2}{*}{$\%$} & 0 & 0 & 0.61 & 0.39 & 0 \\
\hline & future & 45.97 & & 0 & 0 & 0.30 & 0.70 & 0 \\
\hline \multirow{2}{*}{ SI } & historical & 2.65 & \multirow{2}{*}{-} & 0 & 0 & 0.32 & 0.68 & 0 \\
\hline & future & 2.88 & & 0 & 0 & 0.17 & 0.83 & 0 \\
\hline \multirow{2}{*}{$\mathrm{AC}$} & historical & 4.50 & \multirow{2}{*}{$10^{8} \mathrm{~m}^{3}$} & 0 & 0 & 0 & 0 & 1 \\
\hline & future & 4.49 & & 0 & 0 & 0 & 0 & 1 \\
\hline \multirow{2}{*}{$\mathrm{RL}_{10}$} & historical & 4.24 & \multirow{2}{*}{ months } & 0 & 0 & 0 & 0.40 & 0.60 \\
\hline & future & 5.13 & & 0 & 0 & 0 & 0.03 & 0.97 \\
\hline \multirow{2}{*}{$\mathrm{RS}_{10}$} & historical & 20.59 & \multirow{2}{*}{$\%$} & 0 & 0 & 0 & 0.89 & 0.11 \\
\hline & future & 22.25 & & 0 & 0 & 0 & 0.60 & 0.40 \\
\hline
\end{tabular}

Table 5. (c) Performance of fuzzy membership function values in the south region.

\begin{tabular}{|c|c|c|c|c|c|c|c|c|}
\hline \multirow{2}{*}{ Evaluation factor } & \multirow{2}{*}{ Period } & \multirow{2}{*}{ Performance value } & \multirow{2}{*}{ Unit } & \multicolumn{5}{|c|}{ Membership grade } \\
\hline & & & & L1 & L2 & $\mathbf{L 3}$ & L4 & L5 \\
\hline \multirow{2}{*}{$\mathrm{AU}$} & historical & 20.52 & \multirow{2}{*}{$\%$} & 0 & 0.40 & 0.60 & 0 & 0 \\
\hline & future & 28.39 & & 0 & 0.01 & 0.99 & 0 & 0 \\
\hline \multirow{2}{*}{ SI } & historical & 1.29 & \multirow{2}{*}{ - } & 0 & 0.50 & 0.50 & 0 & 0 \\
\hline & future & 2.67 & & 0 & 0 & 0.31 & 0.69 & 0 \\
\hline \multirow{2}{*}{$\mathrm{AC}$} & historical & 0.94 & \multirow{2}{*}{$10^{8} \mathrm{~m}^{3}$} & 0 & 0.02 & 0.98 & 0 & 0 \\
\hline & future & 3.95 & & 0 & 0 & 0 & 0 & 1 \\
\hline \multirow{2}{*}{$\mathrm{RL}_{10}$} & historical & 3.61 & \multirow{2}{*}{ months } & 0 & 0 & 0 & 0.89 & 0.11 \\
\hline & future & 4.43 & & 0 & 0 & 0 & 0.29 & 0.71 \\
\hline \multirow{2}{*}{$\mathrm{RS}_{10}$} & historical & 17.75 & \multirow{2}{*}{$\%$} & 0 & 0 & 0.08 & 0.92 & 0 \\
\hline & future & 25.72 & & 0 & 0 & 0 & 0.18 & 0.82 \\
\hline
\end{tabular}


Table 5. (d) Performance of fuzzy membership function values in the east region.

\begin{tabular}{|c|c|c|c|c|c|c|c|c|}
\hline \multirow{2}{*}{ Evaluation factor } & \multirow{2}{*}{ Period } & \multirow{2}{*}{ Performance value } & \multirow{2}{*}{ Unit } & \multicolumn{5}{|c|}{ Membership grade } \\
\hline & & & & $\mathbf{L} 1$ & $\mathbf{L} 2$ & $\mathbf{L 3}$ & L4 & L5 \\
\hline \multirow{2}{*}{$\mathrm{AU}$} & historical & 14.29 & \multirow{2}{*}{$\%$} & 0.01 & 0.99 & 0 & 0 & 0 \\
\hline & future & 15.44 & & 0 & 0.94 & 0.06 & 0 & 0 \\
\hline \multirow{2}{*}{ SI } & historical & 0.04 & \multirow{2}{*}{-} & 1 & 0 & 0 & 0 & 0 \\
\hline & future & 0.64 & & 0.16 & 0.84 & 0 & 0 & 0 \\
\hline \multirow[b]{2}{*}{$\mathrm{AC}$} & historical & 0 & \multirow{2}{*}{$10^{8} \mathrm{~m}^{3}$} & 1 & 0 & 0 & 0 & 0 \\
\hline & future & 0 & & 1 & 0 & 0 & 0 & 0 \\
\hline \multirow{2}{*}{$\mathrm{RL}_{10}$} & historical & 1.14 & \multirow{2}{*}{ months } & 0 & 0.75 & 0.25 & 0 & 0 \\
\hline & future & 1.64 & & 0 & 0.13 & 0.87 & 0 & 0 \\
\hline \multirow{2}{*}{$\mathrm{RS}_{10}$} & historical & 3.43 & \multirow[b]{2}{*}{$\%$} & 0.41 & 0.59 & 0 & 0 & 0 \\
\hline & future & 12.92 & & 0 & 0 & 0.78 & 0.22 & 0 \\
\hline
\end{tabular}

Table 6. Water resource fuzzy comprehensive assessment in Taiwan.

\begin{tabular}{|c|c|c|c|c|c|c|c|c|}
\hline \multirow{2}{*}{ Region } & \multirow{2}{*}{ Period } & \multirow{2}{*}{ Comprehensive level } & \multicolumn{5}{|c|}{ Membership grade } & \multirow{2}{*}{ SI } \\
\hline & & & L1 & $\mathbf{L 2}$ & $\mathbf{L 3}$ & L4 & L5 & \\
\hline \multirow{2}{*}{ North } & historical & Good (L2) & 0.49 & 0.16 & 0.36 & 0 & 0 & 0.07 \\
\hline & future & Good (L2) & 0.48 & 0.14 & 0.35 & 0.03 & 0 & 0.06 \\
\hline \multirow{2}{*}{ Center } & historical & Poor (L4) & 0 & 0 & 0.31 & 0.41 & 0.28 & 2.65 \\
\hline & future & Poor (L4) & 0 & 0 & 0.15 & 0.51 & 0.34 & 2.88 \\
\hline \multirow{2}{*}{ South } & historical & Fair (L3) & 0 & 0.27 & 0.57 & 0.15 & 0.01 & 1.29 \\
\hline & future & Poor (L4) & 0 & 0 & 0.45 & 0.19 & 0.35 & 2.67 \\
\hline \multirow{2}{*}{ East } & historical & Good (L2) & 0.48 & 0.50 & 0.02 & 0 & 0 & 0.04 \\
\hline & future & Good (L2) & 0.26 & 0.56 & 0.16 & 0.02 & 0 & 0.64 \\
\hline
\end{tabular}

ground reservoir effective capacity of $2.0 \times 10^{8} \mathrm{~m}^{3}$ can help regulate water supply. If this is incorporated into the model simulation, the SI value drops from 2.65 to 1.80 , and the situation levels (see Table 6) increase from $(0,0,0.31,0.41$, $0.28)$ to $(0,0.01,0.43,0.43,0.13)$. While the comprehensive assessment level remains at L4, it has actually improved and has approached L3. In reality, to address the severity of water demand and over-pumping of groundwater in the central region, in recent years relevant government agencies have planned the construction of two reservoirs: Hushan with an effective capacity of $0.52 \times 10^{8} \mathrm{~m}^{3}$ and Tianhua Lake with an effective capacity of $0.48 \times 10^{8} \mathrm{~m}^{3}$, for a total effective capacity of $1.0 \times 10^{8} \mathrm{~m}^{3}$.

c) As for the southern region, the historical comprehensive level is "fair" (L3). This region has the greatest wet/ dry differential in Taiwan, with the dry season (November to April) accounting for only $11 \%$ of total annual rainfall, resulting in the region being very dependent on reservoir regulation to address water shortage problems. The primary demand for water comes from agriculture, and current reservoir effective capacity stands at $7.87 \times 10^{8} \mathrm{~m}^{3}$. Due to insufficient water supplies, agricultural irrigation is conducted on a rotating basis, which has contributed to a degree of control in water needs (currently around $37.9 \times 10^{8} \mathrm{~m}^{3}$ as in Table 2). However, to ensure that agricultural water use doesn't impact residential or industrial use, water shortages frequently result in rice paddies being left fallow. At the same time, the region's current actual water use is largely served by groundwater pumping from 70000 wells pumping $28 \times 10^{8} \mathrm{~m}^{3}$ annually, exceeding annual recharge by 11.9 $\times 10^{8} \mathrm{~m}^{3}$, and over-pumping is most severe in aquaculture operations in coastal areas, resulting in severe subsidence problems. Due to the complexity of water resource demand and supply in the southern region, it is difficult for this 
study to estimate the actual effectiveness of underground reservoirs. Under long-term operation, relevant government agencies have long planned the Meinung Reservoir with an effective capacity of $3.23 \times 10^{8} \mathrm{~m}^{3}$ to stabilize water supply and demand in the southern region.

d) Through validated analysis of the actual water resource situation, the comprehensive assessment model for regional water resources developed by this study is seen to clearly reflect regional water resource conditions and the assessment model can be used to analyze future regional water resources.

\subsection{Future Water Resource Assessment and Prepara- tion of Adaption Options}

a) The results of this study show that, under the effects of climate change and the increase of water demand, Taiwan's renewable water resources in the northern region will drop from historic levels of $157.5 \times 10^{8} \mathrm{~m}^{3}$ to $145.2 \times$ $10^{8} \mathrm{~m}^{3}$ in $2080-2099$, while water demand will rise from $38.8 \times 10^{8} \mathrm{~m}^{3}$ to $42.8 \times 10^{8} \mathrm{~m}^{3}$. Model analysis shows that the performance of each indicator is very close to historical (1979 to 1998) conditions, and that the water resource comprehensive condition is "good" (L2), as shown in Table 6.

b) Future (2080 to 2099) renewable water resources in the eastern region will drop from historical levels of $172.5 \times$ $10^{8} \mathrm{~m}^{3}$ to $162.6 \times 10^{8} \mathrm{~m}^{3}$ while water demand will rise from $23.5 \times 10^{8} \mathrm{~m}^{3}$ to $25.0 \times 10^{8} \mathrm{~m}^{3}$. Analysis shows a small difference from historical levels, and only the extreme event occurrence indicator falls from the historical L2 to L3, while the water resource comprehensive condition remains "good" (L2).

c) In the central region, future annual renewable water resource volume will fall from historical levels of $158.2 \times$ $10^{8} \mathrm{~m}^{3}$ to $133.8 \times 10^{8} \mathrm{~m}^{3}$, while water demand will rise from $65.7 \times 10^{8} \mathrm{~m}^{3}$ to $69.7 \times 10^{8} \mathrm{~m}^{3}$. Without considering underground reservoirs $\left(2.0 \times 10^{8} \mathrm{~m}^{3}\right)$, the future water resource comprehensive condition will be "poor" (L4), as shown in Table 6, primarily due to excessively high water demand and groundwater pumping.

In terms of a future adaptation strategy, this study recommends strengthening the joint use of surface water and groundwater. As mentioned above, given strict controls on groundwater pumping to appropriate levels in the Changhua and Yunlin areas, the effective capacity of underground reservoirs $\left(2.0 \times 10^{8} \mathrm{~m}^{3}\right)$, plus future reservoir construction $(1.0$ $\left.\times 10^{8} \mathrm{~m}^{3}\right)$, combined with current reservoir capacity $(5.34 \times$ $10^{8} \mathrm{~m}^{3}$ ) would provide a total reservoir capacity of $8.34 \times$ $10^{8} \mathrm{~m}^{3}$.

Table 7 provides the adaption options for future water resource management. Given only the aforementioned reservoir capacity $\left(8.34 \times 10^{8} \mathrm{~m}^{3}\right)$ and no change in future water requirements, as in option A, the condition level will remain "poor" (L4). Raising the comprehensive water resource condition to level L3 requires additional consideration of water conservation strategies, as in option B. Under $\mathrm{SI}=1$ conditions, reducing water use by $7.2 \%$ (around 5.02 $\times 10^{8} \mathrm{~m}^{3}$ ) would raise the water resource comprehensive condition to "fair" (L3).

d) The greatest drop in future renewable water resources is in the southern region, where volume will drop from historical levels of $187.1 \times 10^{8} \mathrm{~m}^{3}$ to $150.4 \times 10^{8} \mathrm{~m}^{3}$, and water demand will rise from $37.9 \times 10^{8} \mathrm{~m}^{3}$ to $46.3 \times 10^{8} \mathrm{~m}^{3}$, resulting in a visible deterioration of conditions with water resource comprehensive condition level dropping from "fair" (L3) to "poor" (L4).

The southern region has historically experienced a significant wet/dry distribution gap, and this gap will continue to exist in the future. Therefore, adding reservoir capacity will be a highly effective future adaptation strategy. Given the completion of the $3.23 \times 10^{8} \mathrm{~m}^{3}$ Meinung Reservoir, option $\mathrm{C}$ in Table 7 shows that a comprehensive water resource assessment level can reach "fair" (L3). To achieve a rise to $\mathrm{SI}=1$ would require an additional $4.0 \%$ reduction in water demand (around $1.85 \times 10^{8} \mathrm{~m}^{3}$, as in option D).

e) To differentiate the impact of climate change from the increase of water demand, here we assume that there is no climate change in the future. Table 8 shows the influence of water demand increase on each region's water resources. As compared with Table 6, increase of demand has a great effect upon the island's central and southern regions, whereas climate change has more impact on East, and influence of increased water demands and climate change on North is less significant.

Table 7. Suggested adaptation options for water supply and demand in Taiwan (2080 - 2099).

\begin{tabular}{|c|c|c|c|c|c|c|c|c|c|c|}
\hline \multirow{2}{*}{ Region } & \multirow{2}{*}{ Option } & \multirow{2}{*}{$\begin{array}{l}\text { Extra capacity } \\
\qquad\left(10^{8} \mathbf{m}^{3}\right)\end{array}$} & \multirow{2}{*}{$\begin{array}{c}\text { Demand } \\
\text { reduction } \\
(\%)\end{array}$} & \multirow{2}{*}{ Comprehensive level } & \multicolumn{5}{|c|}{ Membership grade } & \multirow{2}{*}{ SI } \\
\hline & & & & & L1 & L2 & L3 & L4 & L5 & \\
\hline \multirow{2}{*}{ Center } & A & 1.0 & 0 & Poor (4) & 0 & 0.06 & 0.31 & 0.58 & 0.05 & 1.46 \\
\hline & B & 1.0 & 7.2 & Fair (3) & 0.22 & 0.22 & 0.15 & 0.40 & 0.01 & 1.00 \\
\hline \multirow{2}{*}{ South } & $\mathrm{C}$ & 3.23 & 0 & Fair (3) & 0 & 0.20 & 0.63 & 0.17 & 0 & 1.23 \\
\hline & $\mathrm{D}$ & 3.23 & 4.0 & Fair (3) & 0.21 & 0.23 & 0.41 & 0.14 & 0 & 1.00 \\
\hline
\end{tabular}


Table 8. Influence of water demand increase (2080 - 2099) without climate change.

\begin{tabular}{|c|c|c|c|c|c|c|c|c|}
\hline \multirow{2}{*}{ Region } & \multirow{2}{*}{ period } & \multirow{2}{*}{ Comprehensive level } & \multicolumn{5}{|c|}{ membership grade } & \multirow{2}{*}{ SI } \\
\hline & & & L1 & $\mathbf{L 2}$ & $\mathbf{L 3}$ & L4 & $\mathbf{L 5}$ & \\
\hline North & future & Good (L2) & 0.48 & 0.14 & 0.38 & 0 & 0 & 0.09 \\
\hline Center & future & Poor (L4) & 0 & 0 & 0.22 & 0.45 & 0.32 & 3.10 \\
\hline South & future & Poor (L4) & 0 & 0.07 & 0.41 & 0.17 & 0.35 & 2.53 \\
\hline East & future & Good (L2) & 0.47 & 0.50 & 0.03 & 0 & 0 & 0.05 \\
\hline
\end{tabular}

\section{CONCLUDING REMARKS}

This paper presents a comprehensive assessment model for regional water resources under the impact of climate change, which can be used to provide a comprehensive evaluation of regional water resource conditions. The model conducts simulations based on renewable water resources, water demand volume, reservoir facilities, and multiple criteria assessment indicators, and uses fuzzy assessment methods to determine water resource comprehensive conditions. This investigation of Taiwan's four water resource regions indicates that, in the future, Taiwan's northern and eastern regions will maintain good conditions of supply and demand, but the impact on water resource conditions in the central and southern regions will be more obvious. Relevant government agencies should develop prudent long-term adaptation strategies to effectively reduce potential damage from water shortages. Some adaptation options for water resources are suggested in this study to ensure supplies during water shortage occurrences.

Acknowledgements The authors thank the National Taiwan University Global Change Center for providing relevant GCM modeling data, and Japan's JMA/MRI Kyosei4 Modeling Group for providing JMA/MRI modeling data.

\section{REFERENCES}

Arnell, N. W., 1998: Climate change and water resources in Britain. Clim. Change, 39, 83-110, doi: 10.1023/ A:1005339412565. [Link]

Arnell, N. W., 1999: A simple water balance model for the simulation of streamflow over a large geographic domain. J. Hydrol., 217, 314-335, doi: 10.1016/S00221694(99)00023-2. [Link]

Burn, D. H., 1994: Hydrologic effects of climatic change in west-central Canada. J. Hydrol., 160, 53-70, doi: 10.1016/0022-1694(94)90033-7. [Link]

Chen, S. J. and C. L. Hwang, 1992: Fuzzy Multiple Attribute Decision Making, Springer-Verlag, New York, 42-60 pp.

Christensen, N. S., A. W. Wood, N. Voisin, D. P. Lettenmaier, and R. N. Palmer, 2004: The effects of climate change on the hydrology and water resources of the Colorado River Basin. Clim. Change, 62, 337-363, doi: 10.1023/B:CLIM.0000013684.13621.1f. [Link]

Gustard, A., A. Bullock, and. J. M. Dixon, 1992: Low flow estimation in the United Kingdom. Institute of Hydrology, Wallingford, Report No. 108, 88 pp.

Haan, C. T., 1977: Statistical Methods in Hydrology, Iowa State University Press, 378 pp.

Hamlet, A. F. and D. P. Lettenmaier, 1999: Effects of climate change on hydrology and water resources in the Columbia River Basin. J. Am. Water Resour. Assoc., 35, 1597-1623, doi: 10.1111/j.1752-1688.1999. tb04240.x. [Link]

Huang, W. C. and C. L. Hsieh, 2010: Real-time reservoir flood operation during typhoon attacks. Water Resour. Res., 46, W07528, doi: 10.1029/2009WR008422. [Link]

IPCC, 2007: The Fourth Assessment Report (AR4), Available at: http://www.ipcc.ch/.

Kite, G. W., A. Dalton, and K. Dion, 1994: Simulation of streamflow in a macroscale watershed using general circulation model data. Water Resour. Res., 30, 15471559, doi: 10.1029/94WR00231. [Link]

Kitoh, A. and S. Kusunoki, 2008: East Asian summer monsoon simulation by a $20-\mathrm{km}$ mesh AGCM. Climate Dyn., 31, 389-401, doi: 10.1007/s00382-007-0285-2. [Link]

Lane, M. E., P. H. Kirshen, and R. M. Vogel, 1999: Indicators of impacts of global climate change on U.S. water resources. J. Water Resour. Plan. Manage., 125, 194-204, doi: 10.1061/(ASCE)0733-9496(1999)125:4 (194). [Link]

Lin, S. H., C. M. Liu, W. C. Huang, S. S. Lin, T. H. Yen, H. R. Wang, J. T. Kuo, and Y. C. Lee, 2010: Developing a yearly warning index to assess the climatic impact on the water resources of Taiwan, a complexterrain island. J. Hydrol., 390, 13-22, doi: 10.1016/j. jhydrol.2010.06.024. [Link]

Mimikou, M. A., E. Baltas, E. Varanou, and K. Pantazis, 2000: Regional impacts of climate change on water resources quantity and quality indicators. J. Hydrol., 234 , 
95-109, doi: 10.1016/S0022-1694(00)00244-4. [Link]

Mizuta, R., K. Oouchi, H. Yoshimura, A. Noda, K. Katayama, S. Yukimoto, M. Hosaka, S. Kusunoki, H. Kawai, M. Nakagawa, 2006: 20-km-mesh global climate simulations using JMA-GSM model - Mean climate states. J. Meteorol. Soc. Jpn., 84, 165-185, doi: 10.2151/jmsj. 84.165. [Link]

Pike, J. G., 1964: Estimation of annual run-off from meteorological data in a tropical climate. J. Hydrol., 2, 116123, doi: 10.1016/0022-1694(64)90022-8. [Link]

Priestley, C. H. B. and R. J. Taylor, 1972: On the assessment of surface heat flux and evaporation using largescale parameters. Mon. Weather Rev., 100, 81-92, doi: 10.1175/1520-0493(1972)100<0081:OTAOSH > 2.3.C O;2. [Link]

Rees, H. G., K. M. Croker, N. S. Reynard, and A. Gustard, 1997: Estimation of renewable water resources in the European Union. In: FRIEND'97 - Regional Hydrology: Concepts and Models for Sustainable Water Resource Management, Proceedings of the Postojna, Slovenia, Conference, September - October 1997, IAHS Publ. No. 246.

Salas, J. D., J. W. Delleur, V. Yevjevich, and W. L. Lane, 1980: Applied Modeling of Hydrologic Time Series, Water Resources Publications, Colorado, $42 \mathrm{pp}$.

Shiklomanov, I. A., V. Yu. Georgievskii, V. I. Babkin, and Zh. A. Balonishnikova, 2010: Research problems of formation and estimation of water resources and water availability changes of the Russian federation. Russ. Meteorol. Hydrol., 35, 13-19, doi: 10.3103/ S1068373910010036. [Link]
Snyder, R. L., 1992: Equation for evaporation pan to evapotranspiration conversions. J. Irrig. Drain. Eng., 118, 977-980, doi: 10.1061/(ASCE)0733-9437(1992) 118:6(977). [Link]

Thornthwaite, C. W., 1948: An approach toward a rational classification of climate. Geogr. Rev., 38, 55-94.

Tsai, A. Y. and W. C. Huang, 2011: Estimation of regional renewable water resources under the impact of climate change. Paddy Water Environ., doi: 10.1007/s10333011-0274-2, in press. [Link]

Turc, L, 1961: Estimation of irrigation water requirements, potential evapotranspiration: A simple climatic formula evolved up to date. Ann. Agron., 12, 13-49.

US Army Corps of Engineers, 1963: Estimating long-term storage requirements and firm yield of rivers. Technical Bulletin Number 9, Sacramento District, Calif.

Xu, C. Y. and V. P. Singh, 2004: Review on regional water resources assessment models under stationary and changing climate. Water Resour. Manag., 18, 591-612, doi: 10.1007/s11269-004-9130-0. [Link]

Xu, C. Y., J. Seibert, and S. Halldin, 1996: Regional water balance modelling in the NOPEX area: Development and application of monthly water balance models. J. Hydrol., 180, 211-236, doi: 10.1016/00221694(95)02888-9. [Link]

Yu, P. S., T. C. Yang, and C. K. Wu, 2002: Impact of climate change on water resources in southern Taiwan. J. Hydrol., 260, 161-175, doi: 10.1016/S00221694(01)00614-X. [Link]

Zimmermann, H. J., 1991: Fuzzy Set Theory and Its Applications, Kluwer Academic, Boston, 272-280. 